\title{
Complete Response of a Colonic High-Grade Neuroendocrine Carcinoma to Platinum-Based Therapy: Insights from Comprehensive Genomic Profiling
}

Richard Wood ( $\nabla$ rick.wood@dal.ca )

Nova Scotia Health Authority https://orcid.org/0000-0002-2523-890X

Daniel Rayson

Nova Scotia Health Authority

Thomas Arnason

Nova Scotia Health Authority

Ryan C DeCoste

Nova Scotia Health Authority

Daniel Gaston

Nova Scotia Health Authority

Michael D Carter

Nova Scotia Health Authority

\section{Research Article}

Keywords: Neuroendocrine carcinoma, comprehensive genomic profiling, precision medicine, gastrointestinal oncology

Posted Date: November 10th, 2021

DOI: https://doi.org/10.21203/rs.3.rs-1063168/v1

License: (c) (i) This work is licensed under a Creative Commons Attribution 4.0 International License.

Read Full License

Version of Record: A version of this preprint was published at American Journal of Clinical Pathology on October 1st, 2021. See the published version at https://doi.org/10.1093/ajcp/aqab191.305. 


\section{Abstract \\ Background}

Comprehensive genomic profiling (CGP) is an essential tool in precision medicine, providing diagnostic, prognostic, and predictive (therapeutic) information that enables personalized optimal care for cancer patients. We present the case of a 54-year-old woman with stage IV large-cell neuroendocrine carcinoma (LCNEC) of the colon with liver and nodal metastases with complete response to therapy and demonstrate the value of CGP in identifying potential targets for treatment in these tumors.

\section{Results}

CGP performed on the tumor showed pathogenic mutations in multiple oncogenes and tumor suppressor genes including BRCA1, BAP1, and BRAF, high tumor mutation burden (TMB), and high microsatellite instability (MSI-H). Treatment with platinum-based therapy resulted in a complete radiographic response of the metastases, with no evidence of recurrence after 6.5 years. Assessment by Medical Genetics did not identify any evidence of hereditary cancer syndrome. The dramatic response to therapy is likely due to loss of BRCA1 and/or BAP1 function, as deleterious mutations in both genes predict response to platinum-based therapy through exploitation of deficient homologous recombination repair (HRR). The information provided by CGP also suggested potential tumor sensitivity to poly(ADP-Ribose) polymerase inhibitors (PARPi), immunotherapy (IT) and BRAF/MEK inhibitor therapy, should the tumor recur.

\section{Conclusion}

This case highlights the value of CGP in guiding diagnosis and management of rare and aggressive tumors.

\section{Background}

Precision medicine, in oncology, involves tumor nucleic acid sequencing with the goal of identifying therapeutically relevant molecular targets. Sequencing can be limited to a small number of the most clinically relevant genes, or involve a large number of cancer-related genes to more fully characterize the molecular genetic pathways driving tumor biology, a process known as comprehensive genomic profiling (CGP).[1] In addition to the potential benefit of predicting tumor response to treatment and optimizing therapy, molecular profiling can also provide diagnostic and prognostic information and may be of most utility in uncommon or rare tumor types. $[1,2]$

Colonic large cell neuroendocrine carcinoma (LCNEC) is a rare subtype of poorly differentiated neuroendocrine carcinoma (NEC) with poor survival outcomes compared to other neuroendocrine tumors of intestinal origin, with a five year overall survival rate of only $3 \%$ in the setting of metastatic disease. [3] 
We present a case of a patient with metastatic LCNEC who experienced a complete response to platinumbased therapy that has lasted six years at the time of writing. Findings from CGP suggest likely mechanisms underpinning her excellent clinical outcome.

\section{Case Presentation}

In November 2014, a 54-year-old woman presented with weakness, fatigue, abdominal pain, and a palpable right lower quadrant mass. There was no personal or family history of colorectal polyps or cancer of any type. The only prior medical or surgical history was a vaginal hysterectomy for dysfunctional uterine bleeding. She did not smoke and drank alcohol only socially.

\section{Investigations and management}

Computed tomography (CT) imaging identified a $4.5 \mathrm{~cm}$ mass arising in the cecum in association with a thickened colonic wall (Figure 1A). A mesenteric mass $(2.4 \mathrm{~cm})$ and an indeterminate hypoenhancing hepatic lesion $(1.6 \mathrm{~cm})$ were also observed. Colonoscopy demonstrated blood throughout the colon and a unifocal obstructing mass in the right colon.

The patient underwent an urgent, uncomplicated right hemicolectomy, with microscopic and immunohistochemical studies identifying a tumor with morphologic and immunohistochemical features of LCNEC (Figure 2). The mitotic count was 95 mitoses per $2 \mathrm{~mm}^{2}$ and Ki-67 index was 78\%, corresponding with a grade 3 tumor. Expression of mismatch repair (MMR) proteins MLH1 and PMS2 was lost, consistent with high-grade microsatellite instability (MSI-H).

Medical oncology consultation for consideration of adjuvant chemotherapy was sought and further investigations included a repeat short interval CT scan which demonstrated new large volume hepatic metastases measuring up to $8 \mathrm{~cm}$, along with periportal and peripancreatic adenopathy (Figure 1B). A PET scan demonstrated intensely FDG-avid hepatic and nodal disease along with nodal disease above the diaphragm (Figure 1C). An Octreoscan revealed no somatostatin-avidity, consistent with the highgrade nature of the disease process.

Laboratory evaluation revealed elevated hepatic transaminases with ALT of $176 \mathrm{U} / \mathrm{L}$ (normal 0-44) and AST of $352 \mathrm{U} / \mathrm{L}$ (normal 5-45) with normal total and direct bilirubins. CEA was $12.4 \mathrm{ug} / \mathrm{L}$ (non-smoker normal $<5$ ) and LDH was $>7500 \mathrm{U} / \mathrm{L}$ (normal 120-230).

Over the course of the investigations, ECOG status increased from 0 to 2-3 and urgent chemotherapy with paclitaxel $175 \mathrm{mg} / \mathrm{m}^{2}$ and carboplatin $6 \mathrm{mg} / \mathrm{mL} / \mathrm{min}$ area under the curve (AUC) was initiated every 3 days weekly. Paclitaxel was dose-adjusted after cycle 1 to $135 \mathrm{mg} / \mathrm{m}^{2}$ due to peak hepatic transaminases of ALT $253 \mathrm{U} / \mathrm{L}$ and AST $583 \mathrm{U} / \mathrm{L}$. 
The patient had a brisk clinical response to treatment with normalization of functional status and radiologic evidence of disease regression after two cycles. Prior to her sixth and final cycle, hepatic transaminases were almost normalized (ALT $51 \mathrm{U} / \mathrm{L}$, AST $50 \mathrm{U} / \mathrm{L}$ ). Two months following completion of chemotherapy, a CT demonstrated residual small volume hepatic disease with the largest focus measuring $2.2 \mathrm{~cm}$, complete resolution of both periportal and supra-diaphragmatic nodal disease and normalization of hepatic chemistries. Nine months after chemotherapy and without intervening treatment a complete response was documented, which has persisted to this day (Figure 1D).

\section{Comprehensive Genomic Profiling results}

CGP was performed on the resected tumor (next-generation sequencing using the TSO500 gene panel on a NextSeq550 instrument, Illumina). Testing identified pathogenic point mutations in BRCA1 (c.5251C>T; p.Arg1751*, 0.348 mutant allele frequency (MAF)), BRCA2 (c.1813delA, p.lle605fs, $0.392 \mathrm{MAF}$ ), BRCA2 (c.5297delA, p.Asn1766fs, $0.403 \mathrm{MAF}$ ), BAP1 (c.1114C>T, p.GIn372*, $0.396 \mathrm{MAF}$ ) and $B R A F$ (c.1799T>A; p.Val600Glu, $0.364 \mathrm{MAF}$ ), among others (Table 1). Global parameters included extremely high tumor mutation burden (TMB) of 351 mutations per megabase and confirmation of MSI-H status. Additional select pathogenic / likely pathogenic mutations and variants of unknown significance (VUS) are listed in Table 1. No gene amplifications (e.g. in HER2) were identified. The patient was assessed by Medical Genetics and found to be negative for germline mutations in BRCA1/2 and Lynch syndrome genes (MSH2, MSH6, PMS2, MLH1 and EPCAM), confirming the sporadic nature of the mutations and ruling out an inherited cancer syndrome. 
Table 1

Selected tumor mutations interpreted as pathogenic / likely pathogenic, or VUS.

\begin{tabular}{|c|c|c|c|c|}
\hline $\begin{array}{l}\text { Gene/ } \\
\text { Biomarker }\end{array}$ & Mutation & $\begin{array}{l}\text { Allele } \\
\text { Frequency }\end{array}$ & $\begin{array}{l}\text { ClinVar } \\
\text { Significance* }\end{array}$ & Potential Drug Sensitivity ${ }^{\star *}$ \\
\hline$A P C$ & $\begin{array}{l}\text { c. } 1495 \mathrm{C}>\mathrm{T}, \\
\text { p.Arg499* }\end{array}$ & 0.363 & Pathogenic & \multirow[t]{2}{*}{$\begin{array}{l}\text { Macrolide antibiotics } \\
\text { (NCT04454151) }\end{array}$} \\
\hline$A P C$ & $\begin{array}{l}\text { c. } 4348 \mathrm{C}>\mathrm{T} \\
\text { p.Arg1450* }\end{array}$ & 0.368 & Pathogenic & \\
\hline ARID1A & $\begin{array}{l}\text { c. } 2840 \mathrm{del} C \\
\text { p.Pro947fs }\end{array}$ & 0.378 & $N R(P)$ & \multirow[t]{2}{*}{ BET inhibitors (NCT03297424) } \\
\hline$A R I D 1 A$ & $\begin{array}{l}\text { c.3977dupC, } \\
\text { p.Gln1327fs }\end{array}$ & 0.356 & $N R(P)$ & \\
\hline$B A P 1$ & $\begin{array}{l}\text { c. } 1114 C>T, \\
\text { p.Gln372* }\end{array}$ & 0.396 & $N R(P)$ & $\begin{array}{l}\text { PARPi (NCT03297606), platinum- } \\
\text { based therapy }\end{array}$ \\
\hline$B R A F$ & $\begin{array}{l}\text { c.1799T>A; } \\
\text { p.Val600Glu }\end{array}$ & 0.364 & Pathogenic & $\begin{array}{l}\text { RAF/MEK inhibitors } \\
\text { (NCT03297606) }\end{array}$ \\
\hline BRCA1 & $\begin{array}{l}\text { c. } 5251 \mathrm{C}>\mathrm{T} \\
\text { p.R1751* }\end{array}$ & 0.348 & Pathogenic & $\begin{array}{l}\text { PARPi (NCT03297606), platinum- } \\
\text { based therapy }\end{array}$ \\
\hline BRCA2 & $\begin{array}{l}\text { c.1813delA, } \\
\text { p.lle605fs }\end{array}$ & 0.392 & Pathogenic & $\begin{array}{l}\text { PARPi (NCT03297606), platinum- } \\
\text { based therapy }\end{array}$ \\
\hline BRCA2 & $\begin{array}{l}\text { c.5297delA, } \\
\text { p.Asn1766fs }\end{array}$ & 0.4031 & Pathogenic & $\begin{array}{l}\text { PARPi (NCT03297606), platinum- } \\
\text { based therapy }\end{array}$ \\
\hline BRCA2 & $\begin{array}{l}\text { c.5521C>T, } \\
\text { p.Pro1841Ser }\end{array}$ & 0.361 & NR (VUS) & $\begin{array}{l}\text { PARPi (NCT03297606), platinum- } \\
\text { based therapy }\end{array}$ \\
\hline CHEK2 & $\begin{array}{l}\text { c. } 994 C>T, \\
\text { p.Leu332Phe }\end{array}$ & 0.375 & NR (VUS) & $\begin{array}{l}\text { PARPi (NCT03297606), platinum- } \\
\text { based therapy }\end{array}$ \\
\hline CREBBP & $\begin{array}{l}\text { c.5837delC, } \\
\text { p.Pro1946fs }\end{array}$ & 0.337 & Pathogenic & - \\
\hline FANCE & $\begin{array}{l}\text { c. } 929 \mathrm{delC}, \\
\text { p.Pro310fs }\end{array}$ & 0.369 & $N R(P)$ & - \\
\hline $\mathrm{MSH} 2$ & $\begin{array}{l}\text { c. } 1777 \mathrm{C}>\mathrm{T}, \\
\text { p.Gln593* }\end{array}$ & 0.396 & Pathogenic & N/A (protein expression intact) \\
\hline
\end{tabular}

* ClinVar consensus interpretation (www.ncbi.nlm.nih.gov/clinvar). When not reported (NR), the authors' interpretation of pathogenic (P) or VUS is provided in brackets.

${ }^{\star \star}$ Example experimental therapies with ClinicalTrials.gov identifier in parentheses, FDA-approved therapies for large cell neuroendocrine carcinoma in bold

Abbreviations: MSI-H, high-degree microsatellite instability; PARPi, poly-ADP ribose polymerase inhibitor; TMB, tumor mutation burden; VUS, variant of unknown significance 


\begin{tabular}{|c|c|c|c|c|}
\hline $\begin{array}{l}\text { Gene/ } \\
\text { Biomarker }\end{array}$ & Mutation & $\begin{array}{l}\text { Allele } \\
\text { Frequency }\end{array}$ & $\begin{array}{l}\text { ClinVar } \\
\text { Significance }\end{array}$ & Potential Drug Sensitivity ${ }^{\star \star}$ \\
\hline NOTCH2 & $\begin{array}{l}\text { c. } 5356 \mathrm{C}>\mathrm{T} \\
\text { p.Arg1786* }\end{array}$ & 0.419 & $N R(P)$ & \multirow[t]{2}{*}{$\begin{array}{l}\text { Pan-NOTCH inhibitors } \\
\text { (NCT03422679) }\end{array}$} \\
\hline NOTCH3 & $\begin{array}{l}\text { c.124_125dupCC, } \\
\text { p.Cys43fs }\end{array}$ & 0.333 & $N R(P)$ & \\
\hline POLD1 & $\begin{array}{l}\text { c. } 1809 G>A \\
\text { p.Trp603* }\end{array}$ & 0.429 & $N R(P)$ & Immunotherapy (NCT03810339) \\
\hline$R B 1$ & $\begin{array}{l}\text { c.596delT, } \\
\text { p.Leu199fs }\end{array}$ & 0.315 & $N R(P)$ & \multirow[t]{2}{*}{$\begin{array}{l}\text { Aurora kinase inhibitors } \\
\text { (NCT03092934) }\end{array}$} \\
\hline$R B 1$ & $\begin{array}{l}\text { c.1848dupA, } \\
\text { p.Gly617fs }\end{array}$ & 0.279 & $N R(P)$ & \\
\hline SMAD4 & $\begin{array}{l}\text { c.692dupG, } \\
\text { p.Ser232fs }\end{array}$ & 0.361 & Pathogenic & $\begin{array}{l}\text { Vascular disrupter } \\
\text { (NCT04696848) }\end{array}$ \\
\hline SMARCA4 & $\begin{array}{l}\text { c.3952-1G>T, } \\
\text { Splice site }\end{array}$ & 0.415 & $N R(P)$ & $\begin{array}{l}\text { CDK4/CDK6 inhibitors } \\
\text { (NCT03297606) }\end{array}$ \\
\hline TP53 & $\begin{array}{l}\text { c. }-29+1 G>A \text {, Splice } \\
\text { site }\end{array}$ & 0.402 & $N R(P)$ & $\begin{array}{l}\text { IL-2 recombinant fusion protein } \\
\text { (NCT00496860) }\end{array}$ \\
\hline $\begin{array}{l}\text { Global } \\
\text { Parameter }\end{array}$ & Result & & & \\
\hline TMB & High TMB (351 / Mb) & & & Immunotherapy \\
\hline MSI status & MSI-H & & & Immunotherapy \\
\hline \multicolumn{5}{|c|}{$\begin{array}{l}{ }^{*} \text { ClinVar consensus interpretation (www.ncbi.nlm.nih.gov/clinvar). When not reported (NR), the } \\
\text { authors' interpretation of pathogenic }(P) \text { or VUS is provided in brackets. }\end{array}$} \\
\hline \multicolumn{5}{|c|}{$\begin{array}{l}\text { ** Example experimental therapies with ClinicalTrials.gov identifier in parentheses, FDA-approved } \\
\text { therapies for large cell neuroendocrine carcinoma in bold }\end{array}$} \\
\hline \multicolumn{5}{|c|}{$\begin{array}{l}\text { Abbreviations: MSI-H, high-degree microsatellite instability; PARPi, poly-ADP ribose polymerase } \\
\text { inhibitor; TMB, tumor mutation burden; VUS, variant of unknown significance }\end{array}$} \\
\hline
\end{tabular}

\section{Discussion}

Extrapulmonary NEC is a rare, high-grade tumor of neuroendocrine and epithelial differentiation which may arise from cervical, esophageal, colorectal, and prostatic origins among others. [4] Prognosis is typically poor with all-stage five-year survival of $16.3 \%$, dropping to only $3.0 \%$ for stage IV NEC (small-cell and non-small cell combined).[3] Treatment is challenging and relies on chemotherapeutic regimens administered for typical, non-neuroendocrine adenocarcinomas of lung or colorectal origin, with no evidence of recent survival gains, unlike these more common malignancies.[3, 5, 6] 
This case demonstrates a dramatic and durable response of a metastatic colonic LCNEC to platinumbased therapy. While platinum-based therapies are generally recommended for NEC, heterogeneous responses in colorectal high-grade NEC have been observed, with outcomes typically inferior to both large- and small-cell lung NEC.[7] Our patient's remarkable response may have been due to somatic mutations in genes involved in homologous recombination repair (HRR), including two truncating variants in BRCA2 and one each in BRCA1 and BRCA1-associated protein (BAP1). Tumor cells deficient in HRR function are unable to repair double-stranded DNA breaks which leads to platinum sensitivity, as is observed in BRCA-mutant ovarian and prostate cancer.[8, 9] The lack of germline BRCA mutations in our patient highlights the benefit of somatic profiling, as this finding would not have been either suspected or detected by conventional hereditary genetic counselling or germline testing.

Defects in the HRR pathway also predict response to poly-ADP ribose polymerase (PARP) inhibitors (PARPi).[10, 11] The PARP family of proteins repair DNA single strand breaks through base excision repair, playing an especially important role when other DNA repair mechanisms fail, as observed in BRCA1/2-deficient tumors.[12] PARPi are established therapies in BRCA-deficient breast and ovarian cancer, particularly following disease progression on first-line platinum-based therapy.[10,11] In our case, the tumor contained pathogenic mutations in BRCA1 and BRCA2 $(\mathrm{n}=2)$ along with a truncating mutation in BAP1, which is involved in recruitment of PARP to sites of DNA damage.[13] There is minimal data reported regarding the clinical benefit of PARPi in LCNEC but the multiplicity of HRR pathway mutations observed in our patient's tumor suggests that this line of therapy might be considered if disease recurs. [14]

The patient's tumor had a very high tumor mutational burden (351/Mb) with MSI-H status (78\% of sites unstable), both of which are tumor agnostic biomarkers for response to immunotherapy.[15, 16] The high TMB could be due to MLH1 silencing and resulting microsatellite instability, or to the presence of a pathogenic POLD1 mutation (Table 1) which, when indicative of reduced or absent DNA proofreading can lead to extremely high TMB.[17] Tumors with loss of POLD1 or POLE function, similar to MSI-H tumors, can exhibit sensitivity to immunotherapy.[17] There is little data on the effectiveness of immune checkpoint inhibitors in NEC, although clinical trials are ongoing.[18]

Tumors with high TMB may spontaneously regress, presumably due to high levels of tumor neoantigens inciting a robust immune response. A recent case report described a metastatic high-grade NEC in the liver with high TMB that initially spontaneously regressed before progressing.[19] The PD-L1 inhibitor nivolumab then elicited a complete remission for at least twenty-four months.[19] There are also reports of spontaneous regression of Merkel cell carcinoma, a high-grade NEC of the skin.[20]. Thus, immunemediated regression may have played a role in our patient's excellent outcome. It is also possible that chemotherapy served a "priming" role for immune-mediated antineoplastic mechanisms, thereby contributing to the long duration of the complete response. This type of synergistic effect has been observed in patients with various types of solid tumor treated with immunotherapy and systemic chemotherapy.[21] 
The molecular profile of the colonic NEC presented here is comparable to those reported by others. A large recent study found that the pathways most often altered in colorectal NEC are the cell cycle regulation pathway, including loss-of-function mutations in TP53 and $R B 1$, followed by the Wnt signaling pathway (specifically $A P C$ inactivation) and the MAPK and PI3K pathways (including ERBB2 and BRAF). [22] Somatic $B R C A 1$ and $B R C A 2$ mutations were found in approximately $6 \%$ of the tumors analyzed. The molecular profile of colorectal NECs was observed to be more similar to colorectal adenocarcinoma than NECs of other sites, and $76.7 \%$ of colorectal NECs had potentially targetable mutations. The BRAF Val600Glu (V600E) mutation found in our patient's tumor is known to occur in up to $20 \%$ of colorectal NEC[16], suggesting BRAF or combined BRAF/MEK inhibitors could be effective in these cases.

In summary, we present a patient with a rare, high-grade colonic NEC with widespread metastatic disease and poor prognosis who experienced a complete radiographic response to platinum-based therapy lasting six years to date. This optimal outcome was likely mediated through exploitation of a deficient HRR pathway with robust immune activation contributing to tumor clearance. This case highlights the value of CGP for rapid and comprehensive detection of predictive biomarkers to help guide management of oncology patients.

\section{Declarations}

Informed consent has been obtained from the patient to present and publish this work for research purposes.

The authors have no conflicts of interest to declare. This work has received no external funding. This work has not been presented elsewhere.

\section{References}

1. Nesline MK, DePietro P, Dy GK, et al. Oncologist uptake of comprehensive genomic profile guided targeted therapy. Oncotarget. 2019;10:4616-29. https://doi.org/10.18632/oncotarget.27047.

2. Hirshfield KM, Tolkunov D, Zhong H, et al. Clinical Actionability of Comprehensive Genomic Profiling for Management of Rare or Refractory Cancers. Oncologist. 2016;21:1315-25. https://doi.org/10.1634/theoncologist.2016-0049.

3. Shafqat H, Ali S, Salhab M, Olszewski AJ. Survival of Patients With Neuroendocrine Carcinoma of the Colon and Rectum: A Population-Based Analysis. Diseases of the Colon Rectum. 2015;58:294-303. https://doi.org/10.1097/DCR.0000000000000298.

4. Strosberg JR, Coppola D, Klimstra DS, et al. The NANETS Consensus Guidelines for the Diagnosis and Management of Poorly Differentiated (High-Grade) Extrapulmonary Neuroendocrine Carcinomas. Pancreas. 2010;39:799-800. https://doi.org/10.1097/MPA.0b013e3181ebb56f.

5. Clinical practice guidelines in oncology: NCCN guidelines for non-small cell lung cancer V.7. Fort Washington, PA: National Comprehensive Cancer Network. 2019 (https://www.nccn.org. opens in 
new tab).

6. Garcia-Carbonero R, Sorbye H, Baudin E, et al. ENETS Consensus Guidelines for High-Grade Gastroenteropancreatic Neuroendocrine Tumors and Neuroendocrine Carcinomas. Neuroendocrinology. 2016;103:186-94. https://doi.org/10.1159/000443172.

7. Conte B, George B, Overman M, et al. High-Grade Neuroendocrine Colorectal Carcinomas: A Retrospective Study of 100 Patients. Clin Colorectal Cancer. 2016;15:e1-7. https://doi.org/10.1016/j.clcc.2015.12.007.

8. Pan Z, Xie X. BRCA mutations in the manifestation and treatment of ovarian cancer. Oncotarget. 2017;8:97657-70. https://doi.org/10.18632/oncotarget.18280.

9. Byrski T, Huzarski T, Dent R, et al. Pathologic complete response to neoadjuvant cisplatin in BRCA1positive breast cancer patients. Breast Cancer Res Treat. 2014;147:401-5. https://doi.org/10.1007/s10549-014-3100-x.

10. Robson M, Im S-A, Senkus E, et al. Olaparib for Metastatic Breast Cancer in Patients with a Germline BRCA Mutation. N Engl J Med. 2017;377:523-33. https://doi.org/10.1056/NEJMoa1706450.

11. Tew WP, Lacchetti C, Ellis A, et al. PARP Inhibitors in the Management of Ovarian Cancer: ASCO Guideline. J Clin Oncol. 2020;38:3468-93. https://doi.org/10.1200/JC0.20.01924.

12. Rouleau M, Patel A, Hendzel MJ, et al. PARP inhibition: PARP1 and beyond. Nat Rev Cancer. 2010;10:293-301. https://doi.org/10.1038/nrc2812.

13. Kobrinski DA, Yang H, Kittaneh M. BAP1: role in carcinogenesis and clinical implications. Transl Lung Cancer Res. 2020;9:60-6. https://doi.org/10.21037/tlcr.2019.11.24.

14. Rose PG, Sierk A. Treatment of neuroendocrine carcinoma of the cervix with a PARP inhibitor based on next generation sequencing. Gynecologic Oncology Reports. 2019;30:100499. https://doi.org/10.1016/j.gore.2019.100499.

15. Bai R, Lv Z, Xu D, Cui J. Predictive biomarkers for cancer immunotherapy with immune checkpoint inhibitors. Biomark Res. 2020;8:34. https://doi.org/10.1186/s40364-020-00209-0.

16. Fusco MJ, West H (Jack), Walko CM (2020) Tumor Mutation Burden and Cancer Treatment. JAMA Oncol. https://doi.org/10.1001/jamaoncol.2020.6371.

17. Yao J, Gong Y, Zhao W, et al. Comprehensive analysis of POLE and POLD1 Gene Variations identifies cancer patients potentially benefit from immunotherapy in Chinese population. Sci Rep. 2019;9:15767. https://doi.org/10.1038/s41598-019-52414-z.

18. Intergroupe Francophone de Cancerologie Thoracique. (2020) A GCO Trial Exploring the Efficacy and Safety of Nivolumab Monotherapy or Nivolumab Plus Ipilimumab in Pre-treated Patients With Advanced, Refractory Pulmonary or Gastroenteropancreatic Poorly Differentiated Neuroendocrine Tumors (NECs). clinicaltrials.gov.

19. Raufi AG, May M, Greendyk RA, et al (2020) Spontaneous Regression and Complete Response to Immune Checkpoint Blockade in a Case of High-Grade Neuroendocrine Carcinoma. JCO Precision Oncology 1006-11. https://doi.org/10.1200/P0.20.00103. 
20. Walsh NM. Complete spontaneous regression of Merkel cell carcinoma (1986-2016): a 30 year perspective. J Cutan Pathol. 2016;43:1150-4. https://doi.org/10.1111/cup.12812.

21. Emens LA, Middleton G. The Interplay of Immunotherapy and Chemotherapy: Harnessing Potential Synergies. Cancer Immunol Res. 2015;3:436-43. https://doi.org/10.1158/2326-6066.CIR-15-0064.

22. Chen L, Liu M, Zhang Y, et al (2020) Genetic Characteristics of Colorectal Neuroendocrine Carcinoma: More Similar to Colorectal Adenocarcinoma. Clinical Colorectal Cancer. https://doi.org/10.1016/j.clcc.2020.09.001.

\section{Figures}
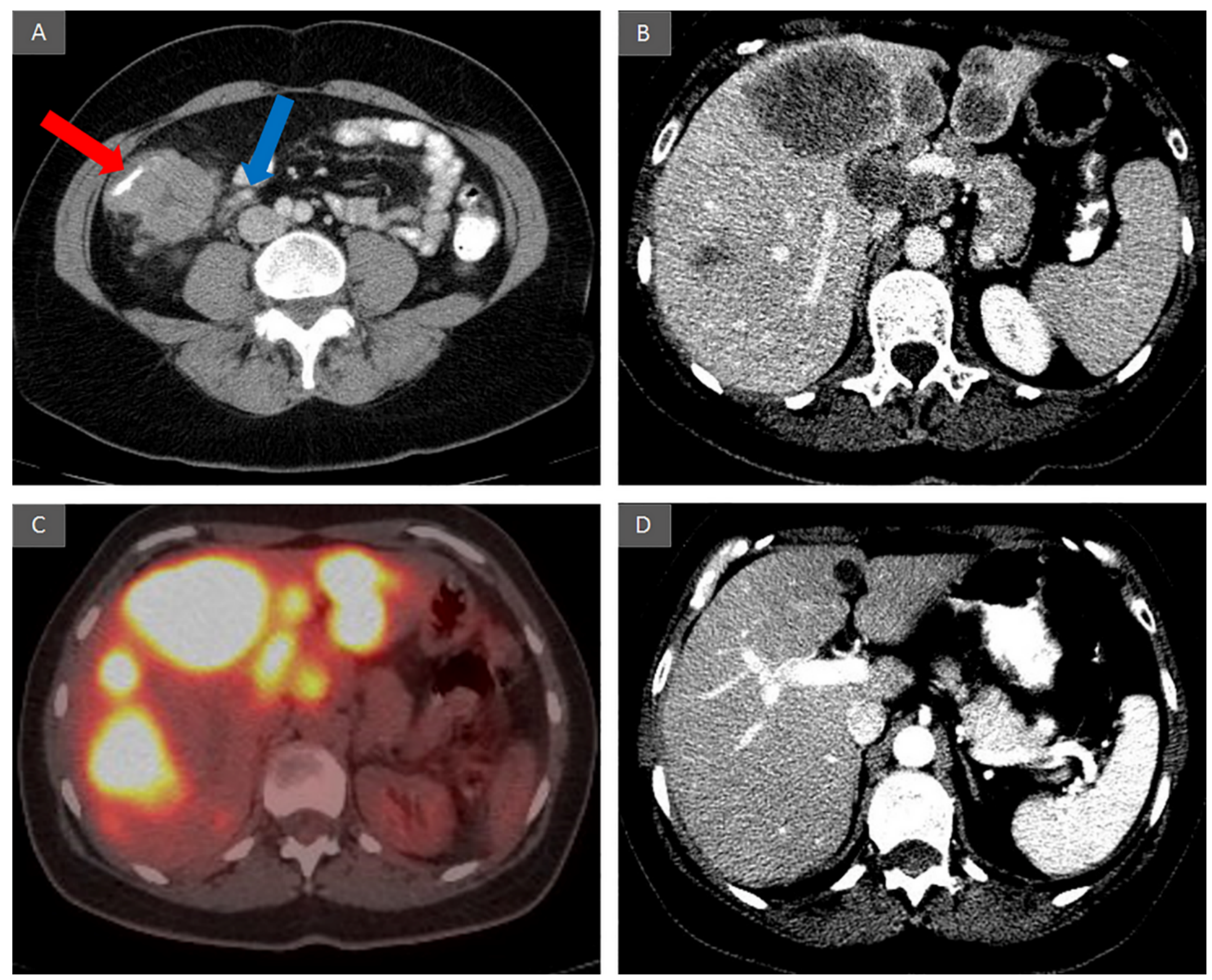

\section{Figure 1}

A) Computed tomography (CT) image of primary cecal tumor (red arrow) and enlarged paracecal lymph node (blue arrow), B) pre-treatment CT image of hepatic metastases, C) pre-treatment positron emission 
transmission-computed tomography (PET/CT) image of 18F-fluorodeoxyglucose (FDG)-avid hepatic metastases, and D) CT image of liver free of lesions 5 years post-treatment.
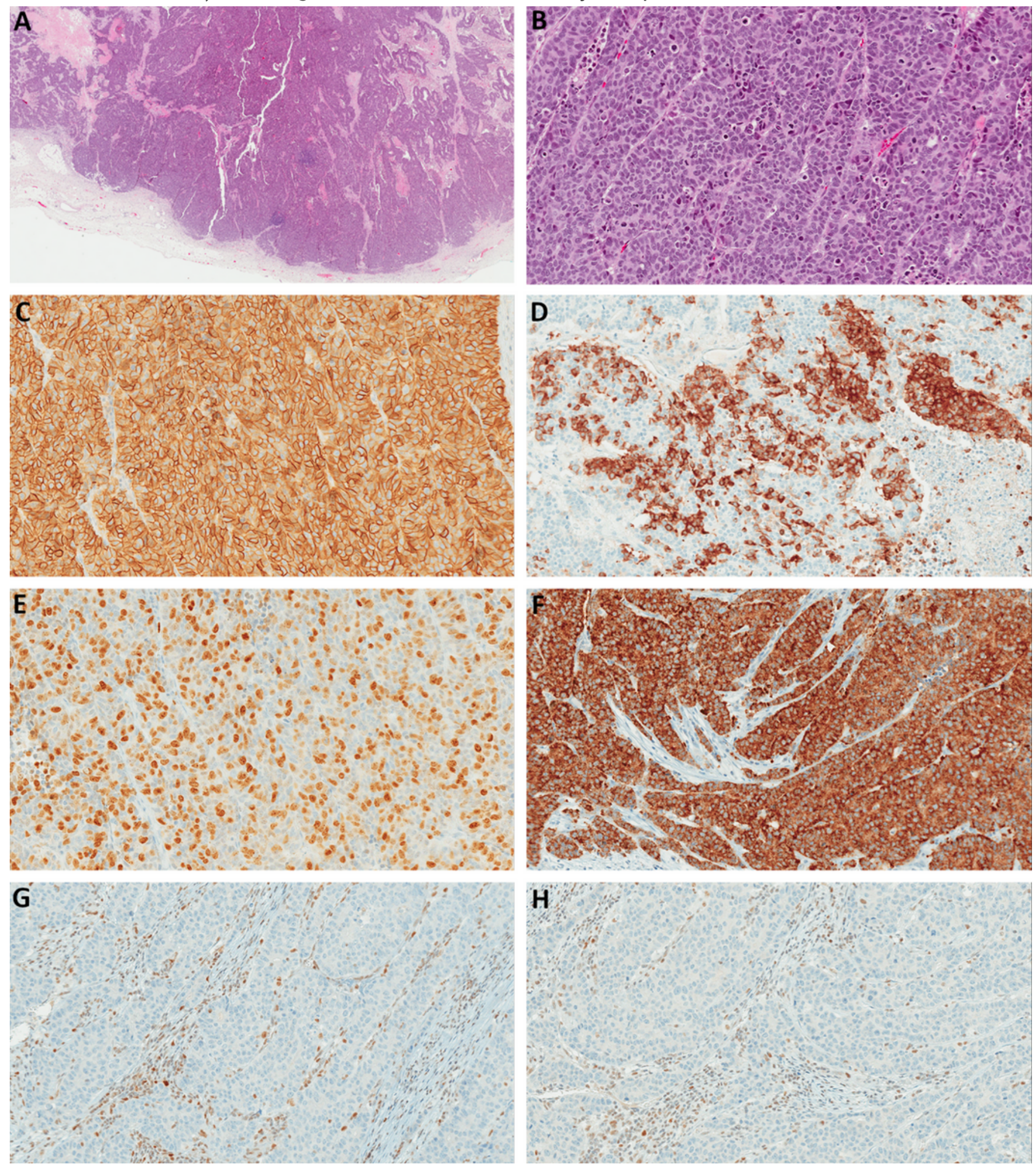

Figure 2

Pathologic examination of right hemicolectomy. H\&E stained sections at A) $5 \mathrm{X}$ and B) $200 \mathrm{X}$ magnification show large cells containing salt-and-pepper chromatin and ample cytoplasm with positive expression of CD56 (C) and focal expression of synaptophysin (D). The Ki-67 index was 78\% (E). Overall 
the features were most consistent with a large cell neuroendocrine carcinoma, grade 3. Expression of mismatch repair (MMR) proteins MLH1 and PMS2 was lost ( $G$ and $H)$, consistent with high-grade microsatellite instability (MSI-H) and positive staining for BRAF V600E confirms the sporadic nature of the MMR defect. The tumor was also positive for AE1/AE3 (not pictured).

\section{Supplementary Files}

This is a list of supplementary files associated with this preprint. Click to download.

- LettertotheeditorJGC.pdf 